\title{
Development of an Assessment Methodology for Hydrocarbon Recovery Potential Using Carbon Dioxide and Associated Carbon Sequestration: Workshop Findings
}

Geologic carbon dioxide $\left(\mathrm{CO}_{2}\right)$ sequestration coupled with enhanced oil recovery using $\mathrm{CO}_{2}$ in existing hydrocarbon reservoirs can increase the U.S. hydrocarbon recoverable resource volume and prevent $\mathrm{CO}_{2}$ release to the atmosphere, potentially limiting $\mathrm{CO}_{2}$ contribution to global warming as a greenhouse gas.

\section{Introduction}

The Energy Independence and Security Act of 2007 (Public Law 110-140) authorized the U.S. Geological Survey (USGS) to conduct a national assessment of geologic storage resources for carbon dioxide $\left(\mathrm{CO}_{2}\right)$ and requested that the USGS estimate the "potential volumes of oil and gas recoverable by injection and sequestration of industrial carbon dioxide in potential sequestration formations" (121 Stat. 1711). The USGS developed a noneconomic, probability-based methodology to assess the Nation's technically assessable geologic storage resources available for sequestration of $\mathrm{CO}_{2}$ (Brennan and others, 2010) and is currently using the methodology to assess the Nation's $\mathrm{CO}_{2}$ geologic storage resources. Because the USGS has not developed a methodology to assess the potential volumes of technically recoverable hydrocarbons that could be produced by injection and sequestration of $\mathrm{CO}_{2}$, the Geologic Carbon Sequestration project initiated an effort in 2010 to develop a methodology for the assessment of the technically recoverable hydrocarbon potential in the sedimentary basins of the United States using enhanced oil recovery (EOR) techniques with $\mathrm{CO}_{2}\left(\mathrm{CO}_{2}\right.$-EOR). In collaboration with Stanford University, the USGS hosted a 2-day $\mathrm{CO}_{2}$-EOR workshop in May 2011, attended by 28 experts from academia, natural resource agencies and laboratories of the Federal Government, State and international geologic surveys, and representatives from the oil and gas industry. The geologic and the reservoir engineering and operations working groups formed during the workshop discussed various aspects of geology, reservoir engineering, and operations to make recommendations for the methodology. The findings of the two groups are discussed below.

\section{Workshop Findings}

\section{Geologic Aspects}

A new assessment methodology could use and build upon the reservoir and associated data already assembled by the USGS National Oil and Gas Assessment (NOGA) project (http://energy.cr.usgs.gov/oilgas/noga/) in previous assessments of undiscovered hydrocarbon resources. The assessment methodology could then assess individual oil reservoirs that are appropriate for $\mathrm{CO}_{2}$-EOR injection techniques at the basin scale to estimate recoverable hydrocarbons using $\mathrm{CO}_{2}$ injection. The assessed reservoirs within each basin could be grouped based on previously defined NOGA Total Petroleum System assessment units with similar lithology and geologic characteristics.

Each assessed reservoir would meet the minimum size criteria used by the NOGA ( 0.5 million barrels of oil), and further characterization would be based on oil-to-gas ratio, depth, temperature, pressure, viscosity, and the API (American Petroleum Institute) gravity of the oil.

The methodology would estimate the original oil in place, if not available from the databases or publicly available sources, and use production data, such as cumulative production, reported reserves, and all other geologic parameters, for each reservoir by consulting commercial, State, and Federal databases and the petroleum geology and reservoir engineering literature for a comprehensive assessment. These same data sources would be consulted for an estimated hydrocarbon recovery factor for primary, secondary (with water floods), and tertiary recovery techniques that would use $\mathrm{CO}_{2}$ injected into the reservoir to improve oil recovery.

The assessment methodology would not include the residual oil zone (ROZ), which is the transition zone at the bottom of oil column, until the ROZ production viability has been established. The ROZ was discussed at the workshop as having future potential for additional oil recovery and therefore would be noted in the assessment for future study.

\section{Reservoir Engineering and Operations Aspects}

A volumetric approach to estimate recoverable hydrocarbon volumes for all conventional reservoirs at the field scale would be used. If sufficient data exist, production-based methods would be used for reservoirs in the primary or waterflood phase to determine estimated ultimate recoverable (EUR) hydrocarbon volumes; this may provide some check on volumetric estimates and in some cases may be the only source for an indirect estimate of the oil-in-place value.

Exponential decline-curve analysis can be used to estimate EUR volumes for most reservoirs that are currently not under pressure maintenance or EOR, and hyperbolic decline-curve analysis can be used for some reservoirs with early decline, strong water drive or horizontal wells. The exponential declinecurve analysis uses a semilogarithmic plot of the cumulative oil recovery versus the oil production rate to estimate the ultimate 


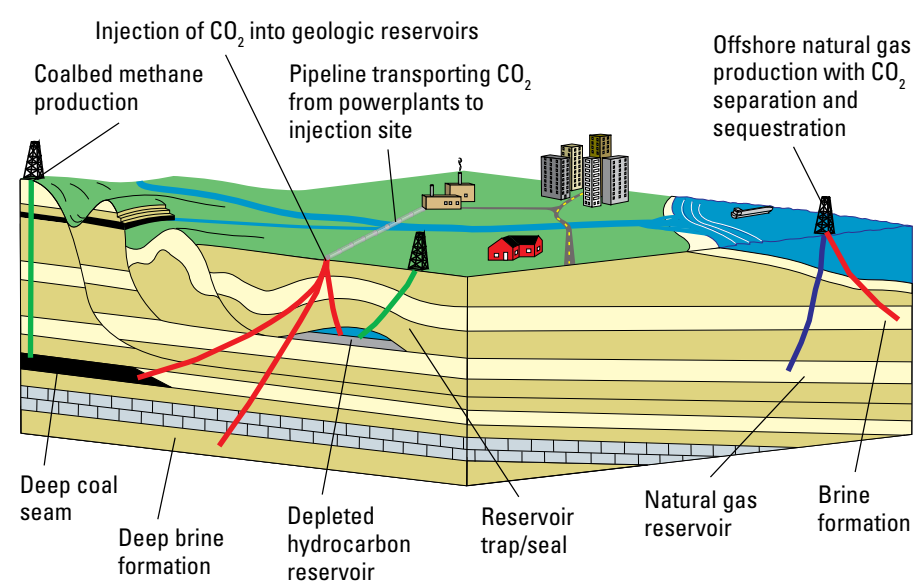

Figure 1. Conceptual diagram showing the geologic sequestration of carbon dioxide (modified from Burruss and Brennan, 2003).

recoverable hydrocarbon volume; the hyperbolic decline curve uses a semilogarithmic graph with the production rate on the log scale and time on the coordinate scale.

Because reservoir pressure and temperature are a function of various geologic and reservoir factors, the reservoirs should be grouped into subsets on the basis of lithology (sandstone versus limestone), permeability (low, medium, and high), and oil gravity (light, medium, and heavy), and a recovery factor range for various groups should be established.

The main focus of the planned assessment would be on reservoirs within the depth range of 3,000 to 13,000 feet because the density of $\mathrm{CO}_{2}$ will be high at these depths; $\mathrm{CO}_{2}$ and oil miscibility that is dependent on oil composition and reservoir conditions (pressure and temperature) can develop; and the practical limitations of compression are based on economic factors and will vary with location and operator. However, some reservoirs outside of the specified depth range may be included if the reservoirs show signs of miscibility and other favorable factors. Although miscibility generally allows more $\mathrm{CO}_{2}$ volume to be sequestered in the reservoirs because of higher displacement efficiency, some of the reservoirs on immiscible flood with sufficiently high recovery and (or) size of the formation also could be included because they potentially could provide a large reservoir volume for carbon sequestration. When performed on the same reservoir under similar conditions, miscible flood will always outperform immiscible flood.

The assessment methodology would consider the latest advances in technology to improve $\mathrm{CO}_{2}$ injection, including but not limited to fracturing, horizontal and multilateral drilling, and 4D (four-dimensional) seismic detection technologies, and could use the best production practices to improve production and recovery factors, such as pattern flooding, isolation of extremely high-permeable zones or streaks, and other reservoir considerations.

During the producing life of a reservoir, although a variable amount of the injected $\mathrm{CO}_{2}$ will stay in the reservoir pore space, some of the $\mathrm{CO}_{2}$ will be recovered with the oil at the surface. The recovered $\mathrm{CO}_{2}$ is recycled after it is separated from the oil, recompressed, and reinjected into reservoir. Therefore, a continuous supply of additional $\mathrm{CO}_{2}$ is required during the operation phase to make up for the loss of $\mathrm{CO}_{2}$ in the reservoir. To prevent fracturing of the reservoir rocks and seal, the reservoir pressure during sequestration of $\mathrm{CO}_{2}$ in EOR operations would not exceed its original value.

The conversion of produced hydrocarbon volumes at the surface to reservoir pore space available for $\mathrm{CO}_{2}$ sequestration uses formation volume factors of oil and gas. Reservoir data in known fields would be evaluated and the evaluated reservoirs would be used as analogs for reservoirs with little to no data.

The ranges of various reservoir and geologic parameters would be established, and Monte-Carlo simulation would be used to determine a probabilistic estimate of potential oil recovery and $\mathrm{CO}_{2}$ sequestered volumes.

\section{Basis for Assessment Methodology}

The USGS Geologic Carbon Sequestration project plans to develop a geology- and engineering-based methodology to assess the potential enhanced oil recovery and $\mathrm{CO}_{2}$ sequestration volumes in oil and gas reservoirs within the sedimentary basins of the United States based on the findings of the USGSStanford workshop.

\section{References Cited}

Brennan, S.T., Burruss, R.C., Merrill, M.D., Freeman, P.A., and Ruppert, L.F., 2010, A probabilistic assessment methodology for the evaluation of geologic carbon dioxide storage: U.S. Geological Survey Open-File Report 2010-1127, 31 p., accessed May 22, 2011, at http://pubs.usgs.gov/ of $/ 2010 / 1127 /$.

Burruss, R.C., and Brennan, S.T., 2003, Geologic sequestration of carbon dioxide-An energy resource perspective: U.S. Geological Survey Fact Sheet 2003-026, 2 p., accessed June 16, 2011, at http://pubs.usgs.gov/fs/fs026-03/.

U.S. Geological Survey, [undated]a, Geologic $\mathrm{CO}_{2}$ sequestration research at the USGS: U.S. Geological Survey, accessed May 22, 2011, at http://energy.er.usgs.gov/health_environment/ co2_sequestration/.

U.S. Geological Survey, [undated]b, National oil and gas assessment: U.S. Geological Survey, accessed May 22, 2011, at http://energy.cr.usgs.gov/oilgas/noga/.

\section{For further information, please contact}

Mahendra K. Verma

U.S. Geological Survey

17842 Wildwood Creek Road

Riverside, CA 92504

Telephone (951) 398-7397

E-mail:mverma@usgs.gov

Peter D. Warwick

U.S. Geological Survey

12201 Sunrise Valley Drive, MS 956

Reston, VA 20192

Telephone: (703) 648-6469

E-mail: pwarwick@usgs.gov

\section{By Mahendra K. Verma and Peter D. Warwick}

